The University of San Francisco

USF Scholarship: a digital repository @ Gleeson Library | Geschke Center

Nursing and Health Professions Faculty Research and Publications

School of Nursing and Health Professions

Fall 2017

\title{
Increasing Empathy and Conflict Resolution Skills through Nonviolent Communication (NVC) Training in Latino Adults and Youth
}

Marcianna Nosek

University of San Francisco, mnosek@usfca.edu

Maite Durán

Follow this and additional works at: https://repository.usfca.edu/nursing_fac

Part of the Community Health and Preventive Medicine Commons

\section{Recommended Citation}

Nosek, Marcianna and Durán, Maite, "Increasing Empathy and Conflict Resolution Skills through Nonviolent Communication (NVC) Training in Latino Adults and Youth" (2017). Nursing and Health Professions Faculty Research and Publications. 120.

https://repository.usfca.edu/nursing_fac/120 


\section{jh JOHNS HOPKINS}

\section{Progress in Community Health Partnerships: Research, Education, and Action}

Progress in Community Health Partnerships (PCHP) is a national, peer-reviewed journal whose mission is to identify and publicize model programs that use community partnerships to improve public health, promote progress in the methods of research and education involving community health partnerships, and stimulate action that will improve the health of people and communities. The first scholarly journal dedicated to Community-Based Participatory Research (CBPR), PCHP is a must for public health professionals and the libraries that serve them. 
Increasing Empathy \& Conflict Resolution Skills through Nonviolent Communication (NVC) Training in Latino Adults and Youth

\section{INTRODUCTION}

As of July 1, 2015, there were 56.6 million people of Latino or Hispanic ${ }^{\mathrm{i}}$ origin comprising $17.6 \%$ of the total population in the U.S., making them the largest minority group in the nation. ${ }^{1}$ Moreover, 15.2 million Latinos resided in California in 2015 making it the state with the largest Latino population including the largest number of foreign born Latinos. ${ }^{1}$ Immigration and acculturation impact experiences of Latinos contributing to challenges such as physical and mental health disparities and separation of families. ${ }^{2-4}$ Children of immigrant families are often torn between their native homes and new communities. ${ }^{2-5}$ Community organizations facilitate empowerment of parents and youth to ease the integration into their new communities and culture. ${ }^{4,5}$ However, Latino youth are at risk for gang involvement, delinquency, teen pregnancy, mental health issues, and substance use as a result of feeling torn between cultures, decreased opportunities, difficulties in school, and broken families and support systems. ${ }^{2-4}$ This paper reports on the initial phase of a community and academic collaborative partnership conducting community based participatory intervention research (CBPR) aimed to increase empathy and conflict resolution skills in Latino adult and youth living in Northern California with the ultimate goal of increasing supportive interpersonal relationships and decreasing delinquent behavior in Latino youth.

\footnotetext{
${ }^{i}$ Although Hispanic includes those who identify Spanish origin, the vast majority in the U.S. migrated from Latin America. For the purpose of this article, it is the preference of the authors to use the term, Latin American or Latino because it denotes a more inclusive attitude.
} 


\section{Youth Delinquency and Supportive Interpersonal Relationships}

Youth who have supportive relationships with parents, teachers, and friends have been shown to be less likely to be either victims or perpetrators of violence. ${ }^{6}$ In addition, researchers have found that parents, teachers, mentors, neighbors, and other caring adults can effect positive change in the lives of young people through role modeling and intervention programs specifically focused on conflict resolution skills and empathy development. ${ }^{7}$ Collaboratively engaging young people and their communities in learning strategies for peacefully navigating conflict is an important step towards building healthy relationships and preventing youth delinquency and interpersonal violence on all levels..$^{6-10}$

Keijsers and colleagues ${ }^{9}$ found that the greater the endorsement of family communication, the less likely the youth in their study engaged in all delinquent behaviors. Similarly, Latino adolescents' perceptions of positive family communication and parental school support has been linked to a decreased likelihood of committing delinquent acts. ${ }^{6}$ Moreover, Moed et al..$^{10}$ determined that lengthy unresolved conflict may lead to behavioral problems, and purported that "expression and regulation of negative emotion is crucial to parent-child relationships generally and to their conflict interactions in particular." (p.1609)

Delinquency among youth and different forms of violence are issues that concern many minority communities and can impact many health outcomes but especially mental health of residents. ${ }^{10}$ Despite mixed quantitative results of school-based efforts to increase conflict resolution skills, ${ }^{8,11}$ in a qualitative study conducted by Shuval and colleagues, ${ }^{12}$ the researchers found that youth acknowledged the positive impact of a school based peer mediation program to "resolve conflict before escalating to fights." p.138 Interventions with parents aimed to reduce delinquency in youth have also been explored. ${ }^{13}$ Using CBPR, Allen et al. ${ }^{13}$ tested the feasibility 
of a parenting program to reduce substance use among Latino youth, and positive results were noted in all outcomes including parent-child conflict demonstrating the effectiveness of CBPR methodologies to enhance effective parenting among Latino immigrants. ${ }^{13}$ Teaching parents and youth effective means to resolve conflict can improve interpersonal relationships thus has the potential to decrease delinquent and/or violent behaviors in youth. Nonviolent Communication training may be one method to improve empathic communication, regulate emotions, and develop conflict resolution skills in both parents and youth.

\section{Nonviolent Communication}

The primary purpose of Nonviolent Communication (NVC) is to resolve interpersonal conflict using empathic communication skills and has been suggested as an effective method for conflict resolution interpersonally and as a bridge between those from different cultures. ${ }^{14-16}$ Empathy has been defined as the capacity to understand and share in another's emotional experience or situation. ${ }^{17,18}$ Empathy, or the lack of it, has been associated with antisocial behavior. ${ }^{18,19}$ NVC seeks to dismantle embedded forms of negative communication and provides a framework for developing an empathetic way of communicating with self and others. Through NVC training individuals are able to identify and diminish reactive and alienating responses to challenging social situations while increasing their skill in empathic conflict resolution and positive relationship building. ${ }^{14-16,20}$

Empirical research conducted on the use of NVC is sparse, although publications have documented its successful use in various settings globally. ${ }^{16,20-30} \mathrm{NVC}$ training in the parole population, ${ }^{22}$ in numerous projects with prison inmates, ${ }^{23-25}$ in nursing students, ${ }^{26,27}$ and in healthcare personnel ${ }^{28-30}$ has demonstrated participants' ability to empathize with self and others and de-escalate tense situations. 
No empirical studies to date have been published on the use of NVC for parents and children. However, books have been published on NVC specifically targeted for parents to improve communication and connection with their children ${ }^{31-33}$ In addition, NVC books have been written for educators, ${ }^{34,35}$ and multiple programs have been established in schools to aid youth in conflict resolution. ${ }^{36,37}$

The purpose of this project was to determine the impact of NVC on the development of empathy and conflict resolution skills in youth and adults living in a Latino immigrant community. The primary research questions were: As a result of NVC training, would participants express an increase in empathy? And, would participants report a sense of increased self-efficacy in resolving conflict? This pilot study was the first step in building collaborative academic relationships in a Latino immigrant community with the aspiration to sustain ongoing community based projects.

\section{METHODS}

\section{Establishing Community Partnership \& Need}

A partnership had been established between the principal investigator (PI) and co-PI through the initial involvement of both in a coalition organized to address alcohol and drug use among youth in the local Latino community. The PI is a nursing and public health professor at a nearby university and represents the healthcare sector on the coalition. The co-PI, a bilingual, bicultural South American immigrant, is a community activist leader who runs the youth group formed by Alcohol Justice, ${ }^{38}$ the organization that hosts the alcohol prevention coalition.

A need for improved communication between parents and youth had previously been identified in earlier focus groups conducted in the community by the co-PI. Additionally, local health officials had identified mental health as a priority need in this population. ${ }^{39}$ Alcohol Justice 
provided the venue to hold the training sessions, and based on the PI's previous experience in NVC research and the co-PI's extensive involvement in the community, a research partnership had begun. This study employed an interpretive qualitative design ${ }^{40}$ to examine participants' experiences of managing conflict and engaging in empathic communication pre and post intervention.

\section{The Community and Sample Recruitment}

Participants were recruited from an immigrant community where the majority of residents are low-income and live in a densely populated area; an estimated 12,000 people live in just over 2 square miles. ${ }^{41}$ Forty-two percent of residents report speaking English not well or not at all with $60 \%$ foreign born, of whom $80 \%$ are from Latin America. A quarter are under the age of 18 and the median income is less than $\$ 44,000$ with $25 \%$ below the federal poverty level (FPL). Fifty-one percent of residents report less than a high school education. ${ }^{41}$

A convenience sample was drawn from two groups that the co-PI is associated with and all reside within the above described immigrant community. The group of adults was recruited using snowball method and was a mix of interested parents and members of a local restorative justice group. The other comprised youth, aged 9 to 17 , who meet weekly at Alcohol Justice ${ }^{38}$ as part of a youth group learning community organizing and advocacy skills with a focus on youth alcohol use prevention.

\section{Protection of Human Subjects}

IRB approval was obtained from the university that the PI is associated with. Signed consent was obtained either in English or Spanish from all adult participants. For minors under the age of 18 , the parent or guardian of the child provided informed consent on behalf of the child, and a signed informed assent was obtained from the minors. 


\section{Procedures}

Intervention. Two separate four-session intensive NVC trainings were conducted over four weeks by two experienced Latino bilingual English/Spanish professional NVC trainers. The trainers, one male and one female, are dedicated community empowerment advocates and have worked extensively on social justice issues in minority populations. Role-playing, card games, and de-briefing of NVC practice experiences were used extensively. These tactics aimed to increase participants' ability to identify feelings and needs of self and others and to become more adept at self-expression and aiding others to more effectively express their emotions and needs. These skills foster empathy and can de-escalate conflict. See Appendix A. for curriculum summary.

Data Collection and Analyses. A demographic questionnaire was administered to participants prior to the training. Qualitative data include verbatim transcripts from multiple recorded focus group discussions. The first ones were conducted prior to any NVC training and included questions such as: In general, how do you handle conflict situations? The adults were also asked, "What attracted you to participate in this training?" The main question asked during the post training session was: How has the use of NVC impacted your ability to resolve conflict? In addition to pre and post training focus groups, a recorded discussion following the first training session was included in the post analysis. All digitally recorded data were transcribed verbatim by an experienced transcriber. Spanish transcriptions were translated by the PI who is proficient in Spanish, and confirmed by a bilingual adult participant who also performed member checking of the analyses. Transcriptions were organized, coded, and interpreted, and narrative and thematic analyses were performed. Salient codes and themes were used for final analyses. ${ }^{40,42}$ 


\section{RESULTS}

\section{Sample Characteristics}

The sample of adults $(n=20)$ included fifteen females. Almost a third $(n=6)$ made less than $\$ 25,000$. Type of work included handyman, carpenter, and physical education teacher for the men, and nanny, housecleaner, medical coder, client services, financial services, store manager, and library assistant for the females. Six did not report profession. See Table 1 for complete adult characteristics.

Eighteen youth participated including ten females. The ages ranged from 9 to 17 with the average being 13, attending grades 3 to $12(M=8)$. Thirteen were born in the U.S., two in Mexico, and two were missing demographic data. Ten reported being Latino or Hispanic; one mixed (White/Latino/Black); and seven did not report race/ethnicity. Of those who reported speaking both Spanish and English, all preferred to speak English. Two youth reported Spanish as preferred spoken language.

\section{Participation in Training}

More youth than adults participated in all four sessions $(n=9$ versus $n=4$, respectively). The average number of sessions attended by the adults was 2.6 vs. 2.78 for youth. See Table 2 .

\section{Qualitative Findings}

\section{Adults' Pre \& Post Training Focus Groups}

Pre-training focus group. Practically all expressed gratitude in general, and/or to have been given the opportunity to "break cycles of violence." Both males and females desired to learn new ways to deal with issues with their spouses, children, extended family, friends, and others. One woman shared, "I am Mexican, I grew up with a totally different form of education; I have two girls and I'm trying since their birth to break the cycles. For me this is like honey to my ears because I want to keep learning new things, especially to apply them in my home." Another 
woman shared how "in adolescence some communication was broken which lead to friction and conflict and raised voices and shouting," and continued, "I think we all need to learn new strategies to enrich our lives and those of others." The yearning to break rooted patterns of ineffective communication not only for her benefit but also for others' was emphasized. Others shared stories of violent family backgrounds, such as this female participant: I come from a totally violent family since I was in my childhood, alcoholic dad, totally violent... and then I follow the same pattern in my family and in the end come from a totally violent family. And I have not been able to handle my emotions so my being here is the best I can be doing. I want to know how to handle my emotions; I want to know how to control my instincts...

Seeking new ways to understand her emotions, she already is feeling a sense of safety to be vulnerable in a community of others with similar needs.

Post training focus groups. Participants shared gratitude for being able to express and understand feelings and needs, for being heard, for being together in community particularly the "Latino community," and to be given the opportunity to "safely and positively" improve their lives. The following themes emerged: 1) Enter the other's shoes; 2) Making a change; and 3) Learning in community.

"Enter the other's shoes." This theme captures the increase in empathy gained through understanding the feelings and needs of others. As one woman shared, "[NVC] has helped me see things more calmly especially at work and to not judge the other person." Learning to make observations in lieu of judgments is a basic NVC technique that helps open oneself up to the experience of others. The following woman expresses this eloquently: 
I think compassionate communication lives up to its name because it generates compassion to understand how the other person feels and put yourself in his situation...Enter the other's shoes to understand more genuinely how they are feeling and to generate a good connection.

This participant exhibits not only one of NVC's major goals - to understand from another's perspective, but also makes it clear that it is for the ultimate outcome of creating a closer, more connected relationship.

"Making a change." Many participants spoke of transformation. In the words of one woman, "We're making a change. We are putting our bit in a change to improve our environment, right? Mainly in our family." This statement captures how each individual can contribute to a lasting change that can spread into one's surroundings, in particular, the family which is so important to the Latino culture known as familismo. Another woman demonstrates a new understanding of how to reduce conflict: "[NVC] gives us the opportunity to identify our feelings because there is a need that is not being covered, or if we know the root where our conflict comes from, it will be easier to meet that need." Changes in how one views the source of conflict is paramount to solving or preventing conflict when it arises. The following excerpt not only demonstrates that change is needed, but that change has already occurred as reflected in the newly acquired insight: "I need to be more quiet, I must change my ways so that if I respect, [others] will respect me."

"Learning in community." Many participants expressed gratitude toward the organizers of the training for bringing people together, and to each other for sharing vulnerabilities. As one woman stated, "it is a blessing to know new faces and learn from each of you." The following 
two statements by a female and male participant, respectively, capture how the training has built community:

'One thing that is super important to me is what we are doing right now, is what we are doing is learning something in community;' and 'I think [NVC] is a tool that can help transform not only the life of a person, but a family, and through the family, impact the community. I think it is a tool that directly impacts the community.'

Again, these reflections demonstrate the thread that is woven between self, family and community. The theme, learning in community overlapped with making changes. Many saw this link, and saw how learning NVC can help enable these imperatives. It is captured in the aforementioned quotes and continued in this statement made by the same male above. "It is important for me to know that there are other people who... want to change the world, and they are willing to do that work even if it is very difficult." He recognizes that change is not easy but he gains strength from knowing that others are working towards the same goals. This sentiment was shared by the following female participant:

...From these resources not only are we to have the power to transform ourselves if we practice, but also our community and that is very important. Our community needs a big push and we can pass it through ourselves and through our family. This depicts how practicing the newly acquired skills results not only in selftransformation but a sense of empowerment that extends to the community. All three adult themes blended together in that one statement, along with an affirmation of what the community needs - a push! 


\section{Youths' Pre \& Post Training Focus Groups}

Pre-training focus groups. Pre-training focus group revealed that the youth used affect, actions, and facial expressions to demonstrate how they may be feeling at a given point in time and a general ability to tune into similar expressions exhibited by peers. One girl shared that it was a "friend" that she may be needing when feeling sad. Moreover, insight into others' needs was demonstrated by the comment: "...when people are like sitting down by themselves, I go next to them because I know they need to talk." However, responses reflected predominately weak skills in conflict resolution between the youth and peers, teachers, and particularly parents. Screaming, withdrawing, avoidance, and even "punching" were tactics mentioned by the youth in response to how they deal with conflict situations.

Post training focus group. The youth were generally less expressive than the adults as expected in their age group. However, there was an overall similar sense of appreciation for learning something new, especially a new way of trying to understand the feelings and needs of others as a way to reduce conflict. A few shared enjoying "when [they] were playing the cards" (referring to a small group card game used to assist players to 'guess' what the feelings and needs are of a person sharing a story of an experience). As one girl stated, "I like the cards because it helped me find what I need when I feel worried and need support. Right now I'm excited because I found support, and yes I liked that."

In relation to others, another young girl expressed, "...now I am more aware of like some signs people use when they are sad and I can ask if they are okay, and if not we can start talking about it and feel better." A similar sentiment was shared by another who learned "to listen to people and know one's needs and those of others." An appreciation for resolving conflict was noted in the following two statements by a boy and girl participant, respectively: "It was good 
because we learned a lot how to deal with things;" and "you can come up with solutions without having to fight."

Prior to the training youth and adults expressed conflict resolution styles in need of improvement, and post focus group narratives demonstrated an increased appreciation for learning new ways to understand one's own emotions and needs as well as those of others. This is a crucial step in the process of resolving conflict. In addition, adults reflected on the healing of being together in community and the benefit of this to help change patterns of behavior in one's self and spreading into the greater community.

\section{LESSONS LEARNED}

What contributed immensely to the successes of this CBPR project was that the co-PI and NVC trainers are bilingual Latinos who are dedicated advocates for Latino community healing and empowerment. The biggest challenge was the intermittent attendance of all four training sessions (e.g., for some, session 2 or 3 was the first attended, and others only attended sessions 1 and 2, etc.). The adults, whose trainings were on Saturday evenings, had lower attendance than the youth since the youth already were convening each week. The adults most likely had extra demands of employment and family obligations with limited leisure time common to immigrant populations. Because of this inconsistency, the original plan to quantitatively measure empathy and self-efficacy in conflict management pre and post training was abandoned. One method to address this could have been to offer a monetary incentive for full participation paid at the last session. Another consideration for future projects would be to offer NVC training to specific parent-youth dyads. ${ }^{43}$ 


\section{CONCLUSION}

Despite the challenges, this initial project was a positive first step in developing an ongoing trusting partnership in order to develop more programs rooted in the needs of the community. Both groups experienced an overall receptivity to the training, and moreover, the adults expressed gratitude for building community. Prior research supports that strategies "for empowerment, sharing power, and growth of [Hispanic/Latino] culture" implemented by healthcare providers and researchers working with Latino populations help "provide a sense of self-confidence and self-reliance" among community members. ${ }^{\text {5.p. } 88}$ This community based project planted that seed in this Latino community, and future projects will continue to aim toward those goals.

\section{References}

1. 2015 Population Estimates. United States Census Bureau. Annual estimates of the resident population by sex, age, race and Hispanic origin for the United States and States: April 1, 2010 to July 1, 2015. [Internet]. Available from: http://factfinder.census.gov/bkmk/table/1.0/en/PEP/2014/PEPASR6H?slice=hisp hisp!year est72014

2. Marsiglia FF, Booth JM, Baldwin A, Ayers S. Acculturation and life satisfaction among immigrant Mexican adults. Adv Soc Work 2013;14(1):49-64.

3. Rubens SL, Fite PJ, Gabrielli J, Evans SC, Hendrickson ML, Pederon CA. Relations between negative life events, time spent in the United States, language use, and mental health outcomes in Latino adolescents. Child Youth Care Forum. 2013;42:389-402

4. Shattell MM, Hamilton D, Starr SS, Jenkins CJ, Hinderliter NA. Mental health service needs of a Latino population: A community based participatory research project. Issues Ment Health Nurs 2008;29:351-370.

5. Amendola MG. Empowerment: Healthcare professionals' and community members' 
contributions. J Cult Divers. 2011;18(3):82-89.

6. Davalos DB, Chavez EL, Guardiola RJ. Effects of perceived parental school support and family communication on delinquent behaviors in Latinos and white non-Latinos. Cultur Divers Ethnic Minor Psych 2005;11(1):57-68.

7. Galinsky E, Salmond. K. Youth and violence: Students speak out for a more civil society. New York: Families and Work Institute; 2002.

8. Hawkins JD, Catalano RF, Kosterman R, Abbott R, Hill KG. Preventing adolescent healthrisk behaviors by strengthening protection during childhood. Arch Pediatr Adolesc Med 1999; 153:226-234.

9. Keijsers L, Frijns T, Branje SJT, Meeus W. Developmental links of adolescent disclosure, parental solicitation, and control with delinquency: Moderation by parental support. Dev Psychol 2009; 45(5):314-1327.

10. Moed A, Gershoff ET, Eisenberg N, Hofer C, Losoya S, Spinrad TL, et al. Parent-adolescent conflict as sequences of reciprocal negative emotion: Links with conflict resolution and adolescents' behavior problems, J Youth Adolescence 2015; 44:1607-1622

11. Shuval K, Pillsbury CA, Cavanaugh B, McGruder L, McKinney CM, Masssey Z, et al. Evaluating the impact of conflict resolution on urban children's violence-related attitudes and behaviors in New Haven, Connecticut, through a community-academic partnership. Health Educ Res 2010;25:757-768.

12. Shuval K, Massey Z, Caughy MO, Cavanaugh B, Pillsbury CA, Groce N. "I live by shooting hill" - A qualitative exploration of conflict and violence among urban youth in New Haven, Connecticut. J Health Care Poor Underserv 2012;23(1):132-143.

13. Allen ML, Hurtado GA, Jin Yon K, Okuyemi KS, Davey CS, Marzak MS, et al. Feasibility of a parenting program to prevent substance use among latino youth: A community based participatory research study. Am J Health Promot 2013;27(4):240-244.

14. Rosenberg MB. Nonviolent communication: A language of life. 2nd ed. Encinitas: Puddle Dancer Press; 2005.

15. Rosenburg MB. Speak Peace in a world of conflict. What you say next will change your world. Encinitas: Puddle Dancer Press; 2005. 
16. KÖK H. Nonviolent Communication in Political Conflicts [Internet]. USAK Yearbook Internat Politics and Law 2009;2:349-362. Available from: http://www.usak.org.tr/images_upload/files/makale17_2009.pdf

17. Blake SM. A step toward violence prevention: Non-violent communciation as part of a college curriculum. Boca Raton:Florida Atlantic University; 2002.

18. Jolliffe D, Farrington DP. Empathy and offending: A systematic review and meta-analysis. Aggress Violent Behav 2004;9:441-476.

19. Bazemore G, Stinchcomb J. A civic engagment model of reentry: Involving community through service and restorative justice. Fed Probat 2004;68(2);1-14.

20. Koegel R. Partnership education and Nonviolent Communication [Internet]. Encounter: Educ Meaning Soc Justice 2002;15(3):2-4. Available from: http://www.nonviolentcommunication.com/pdf_files/partnership_education_rkoegel.pdf

21. Dzaferovic M. Nonviolent Communication, empathy and assertion as modern strategies in the study of overcoming conflicts. Metodicki obzori, 2012;7:105-116. UDK: 159.913:159.923.5

22. Marlow E, Nyamathi A, Grajeda W, Baile N, Weber A, Younger J. Nonviolent communication training and empathy in male parolees. J Correct Health Care 2012;18(1):819.

23. BayNVC Restorative Justice Project [Internet] Available from: http://www.baynvc.org/restorative_justice.php

24. Freedom Project Seattle. [Internet]. Available from: http://freedomprojectseattle.org/

25. Oregon Prison Project. [Internet]. Availabe from: http://rosecitynvc.org/programs/opp/

26. Nosek M. Nonviolent Communication: A dialogical retrieval of the ethic of authenticity. Nurs Ethics 2012;19(6):829-837.

27. Nosek M, Gifford L, Kober B. Nonviolent Communication training increases empathy in baccalaureate nursing students: A mixed method study. J Nurs Educ Pract 2014;4(10):1-15.

28. Reimer D. Creating sanctuary: Reducing violence in a maximum security forensic psychiatric hospital unit. J Forensic Nurs 2009;15(1):1-5

29. Museux A, Dumont S, Careau E, Milot E. Improving interprofessional collaboration: The effect of training in nonviolent communication. Soc Work Health Care 2016;55(6):427-439. 
30. Sears M. Humanizing health care. Creating cultures of compassion in health care with Nonviolent Communication. Encinitas: Puddle Dancer Press; 2010.

31. Hart S, Hodson VK. Respectful parents, respectful kids. 7 Keys to turn family conflicts into co-operation. Encinitas: Puddle Dancer Press; 2006.

32. Kashtan I. Parenting from your heart. Sharing the gifts of compassion, connection and choice. Encinitas: Puddle Dancer Press; 2004.

33. Rosenburg M. Raising children compassionately. Parenting the Nonviolent Communication way. Encinitas: Puddle Dancer Press; 2004

34. Rosenburg M. Teaching children compassionately. How students and teachers can succeed with mutual understanding. Encinitas: Puddle Dancer Press; 2004.

35. Hart S, Hodson VK. The compassionate classroom. Relationship based teaching and learning. Encinitas: Puddle Dancer Press; 2004.

36. Hart S. Nonviolent Communication in schools. [Internet]. Available from: https://www.cnvc.org/about-us/projects/nvc-schools/nonviolent-communication-schools

37. Savic NI. Overview of the projects implementing the programs of Nonviolent Communication in the schools and kindegartens in Serbia and Montenegro in the period 1993-2008 [Internet]. 2009. Available from: https://www.cnvc.org/about-us/projects/nvcschools/nvc-schools-serbia-and-montenegro/nvc-schools-serbia-and-montenegro

38. Alcohol Justice. The Industry Watchdog [Internet] https://www.alcoholjustice.org/

39. Baskett LH. 2013 Community health needs assessment. Kaiser Foundation Hospital Available from: https://share.kaiserpermanente.org/wp-content/uploads/2013/09/San-RafaelCHNA_2013.pdf

40. Benner P. Interpretive phenomenology: Embodiment, caring and ethics in health and illness. Thousand Oaks: Sage; 1994.

41. Crispell M. Center for community innovation. University of California Berkeley. [Internet]. 2015. Available from: http://iurd.berkeley.edu/uploads/Canal_FINAL.pdf

42. van Manen M. Researching the lived experience. Albany: State University of New York Press; 1990.

43. Ayon C, Baldwin A, Umana-Taylor AJ, Marsiglia FF, Harthum M. Agarra el momento/seize the moment: Developing communication activities for a drug prevention intervention with and for Latino families in the US Southwest. Qual Soc Work March 2016;15:281-299. 
Table 1. Adult Sample Characteristics $(\mathbf{N}=\mathbf{2 0})$

\begin{tabular}{|c|c|c|c|}
\hline Age (mean $\pm S D$, range $)(n=17)$ & $\begin{array}{l}43.7 \pm 13.2 \\
(17-61)\end{array}$ & $\begin{array}{l}\text { Gender }(\mathrm{n}, \%) \\
\text { Male } \\
\text { Female }\end{array}$ & $\begin{array}{c}5(25 \%) \\
15(75 \%)\end{array}$ \\
\hline $\begin{array}{l}\text { Self Reported Ethnicity }(\mathrm{n}, \%) \\
\text { Latino or Hispanic } \\
\text { Mestizo } \\
\text { Italian } \\
\text { NR }\end{array}$ & $\begin{array}{ll}15 & (75 \%) \\
2 & (10 \%) \\
1 & (5 \%) \\
2 & (10 \%)\end{array}$ & $\begin{array}{l}\text { Country of Origin (n, \%) } \\
\text { Mexico } \\
\text { Guatemala } \\
\text { El Salvador } \\
\text { United States } \\
\text { Ecuador } \\
\text { Peru } \\
\text { Italy } \\
\text { NR }\end{array}$ & $\begin{array}{l}8(40 \%) \\
3(15 \%) \\
2(10 \%) \\
2(10 \%) \\
1(5 \%) \\
1(5 \%) \\
1(5 \%) \\
1(5 \%)\end{array}$ \\
\hline $\begin{array}{l}\text { Language(s) Spoken (n, \%) } \\
\text { English \& Spanish } \\
\text { Spanish only } \\
\text { English only } \\
\text { English, Spanish, Italian } \\
\text { English, Spanish,"little French" } \\
\text { NR }\end{array}$ & $\begin{array}{ll}10 & (50 \%) \\
6 & (30 \%) \\
1 & (5 \%) \\
1 & (5 \%) \\
1 & (5 \%) \\
1 & (5 \%)\end{array}$ & $\begin{array}{l}\text { Preferred Language (n, \%) } \\
\text { (Spoken \& Written) } \\
\text { Spanish } \\
\text { Spanish \& English } \\
\text { English } \\
\text { Castellano } \\
\text { NR }\end{array}$ & $\begin{array}{l}9(45 \%) \\
6(30 \%) \\
3(15 \%) \\
1(5 \%) \\
1(5 \%)\end{array}$ \\
\hline $\begin{array}{l}\text { Highest Level of Education (n, \%) } \\
3 \text { years } \\
9 \text { years } \\
12 \text { years/high school/secondary } \\
16 \text { years/some college/university } \\
\text { Currently in community college } \\
\text { Nursing degree } \\
\text { Business degree } \\
\text { MBA } \\
\text { Undefined masters }\end{array}$ & $\begin{array}{l}1(5 \%) \\
1(5 \%) \\
8(40 \%) \\
6(30 \%) \\
1(5 \%) \\
1(5 \%) \\
1(5 \%) \\
1(5 \%) \\
1(5 \%)\end{array}$ & $\begin{array}{l}\text { Income } \\
<25,000 \\
25,000-50,000 \\
50,000-75,000 \\
\text { NR } \\
\text { Employment } \\
\text { Full time } \\
\text { Part time } \\
\text { Unemployed } \\
\text { NR }\end{array}$ & $\begin{array}{l}7(35 \%) \\
6(30 \%) \\
1(5 \%) \\
6(30 \%)\end{array}$ \\
\hline $\begin{array}{l}\text { Marital Status } \\
\text { Married } \\
\text { Single } \\
\text { Divorced } \\
\text { Separated } \\
\text { NR }\end{array}$ & $\begin{array}{ll}5 & (25 \%) \\
8 & (40 \%) \\
3 & (15 \%) \\
1 & (5 \%) \\
3 & (15 \%)\end{array}$ & $\begin{array}{l}\text { Number of Children per } \\
\text { Adult Participant } \\
\text { One } \\
\text { Two to three } \\
\text { Four - six } \\
\text { Total \# children }\end{array}$ & $\begin{array}{ll}2 & (9.5 \%) \\
12 & (57 \%) \\
1 & (4.7 \%) \\
37\end{array}$ \\
\hline $\begin{array}{l}\text { Children } \\
\text { Yes } \\
\text { No }\end{array}$ & $\begin{array}{c}16(76 \%) \\
5(24 \%)\end{array}$ & $\begin{array}{l}\wedge \text { Ages of Children } \\
<1 y-5 \\
6-10 \\
11-15\end{array}$ & $\begin{array}{l}3 \\
2 \\
6\end{array}$ \\
\hline Mean age of child & 20 & $\begin{array}{l}16-20 \\
20-30 \\
>30\end{array}$ & $\begin{array}{l}9 \\
13 \\
6\end{array}$ \\
\hline
\end{tabular}

* Includes one parent attending the youth session; NR = None reported

$\wedge$ This describes how many adults have children in each age category; e.g., 3 adults have children between the ages of $<1$ to 5 years of age, etc. 
Table 2. Number of Sessions Attended in Adult and Youth Groups

\begin{tabular}{c|c|c}
\hline Number of Sessions Attended & Adults (n) & Youth (n) \\
\hline 1 & 4 & 5 \\
2 & 5 & 3 \\
3 & 6 & 1 \\
4 & 4 & 9 \\
\hline Mean (SD) & $2.53 \pm 1.02$ & $2.78 \pm 1.35$ \\
\hline
\end{tabular}

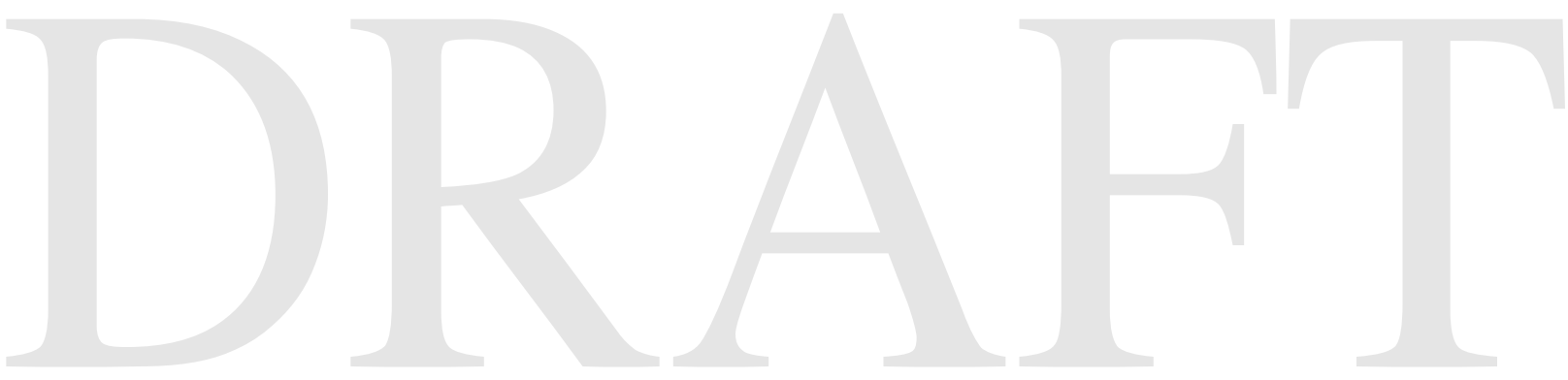

